\title{
Me, Religion and Culture
}

\author{
Amos Avny \\ Omnidev International, Yehud, Israel \\ Email: amosav@smile.net.il
}

How to cite this paper: Avny, A. (2019) $\mathrm{Me}$, Religion and Culture. Open Access Library Journal, 6: e5735.

https://doi.org/10.4236/oalib.1105735

Received: August 26, 2019

Accepted: September 15, 2019

Published: September 18, 2019

Copyright $\odot 2019$ by author(s) and Open Access Library Inc.

This work is licensed under the Creative Commons Attribution International License (CC BY 4.0).

http://creativecommons.org/licenses/by/4.0/

\begin{abstract}
$\mathrm{Me}$ - the creative Individual, Religion - the uncontainable Universe, and Culture-the spiritual sphere that envelopes us, constitutes the triad that leads the article. Religion and Culture represent those human soft aspects that usually are not examined by rationalists such as economists and politicians. Both superhuman systems of faith and worship are carried out by human beings, who are the initiators and the motivators of those systems. Individuality is imperative, because it conceives creativity and innovation. It should be encouraged as long as it keeps a dynamic balance between personal rights, obligations and responsibilities. Marx's negative opinion on Religion is denied because of the evident that religion was and still is a crucial response to human very antic need. From early days of humanity, people were in search of mysteries, unhuman events and disastrous occurrences. God and his postulates were found to be the proper answer. Culture, which is the manifestation of human physical and spiritual achievement, is a crucial ingredient of every social structure. Frequently it is mistreated because it is intangible and deals with values other than money. For ensuring success and further expansion, Culture must begin at home, before looking to global arenas. Its proponents must learn to cope with the contemporary dangers that emerged from the fast advancement of technology. The article ends with an optimistic view and a hope that the Western Civilization would regain its world's leadership position, provided the required reconstruction steps will be taken.
\end{abstract}

\section{Subject Areas}

Philosophy, Sociology

\section{Keywords}

Individualism, Religion, Culture, Post-Modern Era, Western Civilization, Megatrends, Human-Being, Faith, Change, Uncertainty, Creativity and Vision 


\section{Preface}

Everyone is entitled to serve his/ her God, My God equals Sigma [1] ( $\Sigma$ ) of the Unknowns, Since the number of Unknowns is Unknown, thus, $\underline{M y \text { God equals Unknown in power of } 2=\underline{U_{n k n o w n}}}$

(A. Avny) [2]

A recent discussion on the role of Religion and Culture, and their importance for the Post-modern society, had driven the Author to participate and contribute his ideas, feelings and attitudes about such a basic and transcendental issue. However, this is done from the Individual's point of view, as he sees it as key factor in comprehending world phenomena.

Although the Author is not a religious person he still states, as is quoted: "I am a believer." He is a believer because believing or having a Faith is a personal leverage and an empowering force that helps in bad times. Thus, the Author completes his statement by offering his version of God. For him "God equals to the Unknown in power of 2," while the believing's core element is the supreme product of the creation-the Human-being.

In comparison with religious individuals, who argue that God and his serving religions are above the law of the land, and are entitled to some special privileges, the Author claims that for him Human-beings, singular and plural, are the outmost supreme entities, whom we have to serve and take care of.

Since Astronomy and other nature sciences are beyond the Author's areas of inquiry, he does not know how Earth had been created. With regard to the evolution of human-beings he prefers to follow Charles Darwin's teaching "On the Origin of Species." By presenting these basic principles it seems that the principal grounds for the detailed discussion have been fairly laid, enabling to proceed to the main topic of the essay.

\section{Introduction}

$\mathrm{Me}$ - the Creative Individual, Religion-the endless and uncontainable Universe, and Culture-the spiritual sphere that envelopes us from A to $Z$, were posted as the essay's title, for indicating the author's purpose. Many works were dedicated to the rational and materialistic aspects of life, it makes sense, therefore, paying more attention to the other non-materialistic parts of our life. This is, therefore, the reason how this title was chosen.

Religion and Culture are, almost like Siamese Twins, two components of the same matter. Religion does not contain all the cultural aspects and Culture does not contain all the religious commands and habits of human life. Both are carried out by human beings, who are the initiators and the motivators for those systems. The whole triad is constructed of conducts, practices and customs, that form together a spiritual and emotional body of intangible values. It should be remembered that originally, religion is not connected to any particular God and it is not obliged to follow any national tendency. Thus, religion and culture are 
both, God, and nation, race, color and gender, blind. Of course, there are some connections, linkages and mutual influences, but in principle, each of those triad has its own reasons and justifications for existing.

\section{What Religion Means?}

"Religious suffering is, at one and the same time, the expression of real suffering and a protest against real suffering. Religion is the sign of the oppressed creature, the heart of the heartless world and the soul of soulless conditions. It is the opium of the people" (Karl Marx) [3].

\section{Definitions}

A. "the belief in and worship of a superhuman controlling power-God or Gods."

B. "a particular system of faith and worship" [4].

Karl Marx negative opinion on religion may be used as a good starting point for the discussion. The above opinion well reflects Marx sorrows and rage because of the poor "oppressed creatures"-children, females and less-fortunate males -who were forced to make their living by working at the sweat-shops of the newly established industrial factories. However, these abusive conditions were the outcomes of an economic occurrence-the industrial revolution, which occurred along the $19^{\text {th }}$ Century. Similar conditions took place in America, two hundred years before, during the slavery period. Unfortunate people had suffered for years, in America and in Europe, being abused by "heartless" and "soulless" supervisors and masters. Religious clergies, ministers and bureaucrats had also participated in similar kinds of children abuse.

Although Marx anger was understandable and justified, but it reflects only one side of the issue-the supply side. Since he was a rational philosopher, Marx failed conversing with Sigmund Freud, who was one of the prominent psychologists of that time. Unfortunately, Marx as a rationalist, did not realize how strong and deep was, and still is, the demand for religion. The demand for religion is especially strong and compelling by the two contradicting ends of human society. The very rich and wealthy seek spiritual fulfilment while the poor, the abused and the unprivileged look for salvation and gratification.

Curiosity and fright, suffering and panic, usually are the fore-parents of the request for religion. Oddly enough, as strongly these feelings are so growing their demand for an external "superhuman controlling power" was. From early days of history, from Adam and Eve in Paradis, they were challenged by their curiosity. They were overwhelmed by the transcendental entity that told them what to do or not to do. People all over the globe wonder who is responsible for the miracles, disasters, overwhelming events, and surprising catastrophes occurred upon Mamma Earth and Father Nature. They search for answers and seek some transcendental addresses that will meet their needs. For most believers Almighty God is the reliable entity, the one that provides satisfactory an- 
swers to their wonderings.

Thus, religion is the proper way for worshiping and thanking Him for his gracious Mercies. The fact that religions are spread all over the world, they have a significant role within all Huntington's nine Civilizations and they last thousands of years, just indicate how crucial are they for the human kind. As the demand for religious services is so high it indicates on its cruciality and its significantly necessity for people. The formal religious establishments take advantage of this human need and use it for building large and powerful organizations that aim to last forever. Like other powerful organizations the religious ones developed their own power centers, learning seminars, churches, temples, monasteries, mosques and various institutions. These dedicated facilities, assisted by devoted personnel and faithful bureaucracy run the religious show and ensure its continuity. The question whether this "particular system" ensures the existence of "faith and worship," as pretends the second definition, remains opened. The above analysis explains the importance of the religion's Demand side and how it determines the volume and the quality of the religious services. Thus, being a primary need and an almost unreplaceable human urge, causes religion to fulfil one of the upmost stands of human society. Unfortunately, Karl Marx failed to see the emotional aspects of religion, missed the effects of its demand and therefore, erroneously, has compared it with opium, rather than a kind of therapy of the poor's suffering.

An interesting lessen could be learnt from the Author's personal experience regarding the above point.

In the early 1980s, when first visiting South-East Asia, he was very impressed from the Buddhist temples' golden caps. The tour guide has explained that the religious tradition askes the poor peasants to donate every holiday a little sum of money for buying a little golden leaf, to be stuck to the temple's roof. Naturally the Author, as a young rationalist, negated this custom and referred to Karl Marx's opium connotation.

Some years later, when working in Sub-Sahara-Africa, the Author had observed that every Sunday, the poor African peasants, wore their best outfits and as family went miles together for participating in their church Sunday service. One may argue that this is another case of using the church as opium for the Africans.

However, this time, the Author opened his mind and due to his closed acquaintance with the peasants he was able to disclose the emotional hidden drives that motivated them to join the church/temple services. By sticking a small golden leaf to God's Temple, the poor peasants grew and became donners, who stand on a higher level than receivers. This minute donation fulfils the peasants' chest, pride and satisfaction and had given them some minutes of happiness. The same thing referred to joining the distanced church in Sundays.

The African peasants felt better and were emotionally elevated when Joining the church at Sunday, because that act gave them some transcendental uplifted 
satisfaction and allowed them to feel some happy moments. It seems that for those poor people, happiness is so scarce and rare that every effort justifies its prolonging.

The lesson learnt from the above two cases indicates that for better understanding religious matters one should employ his/her emotional and spiritual capacities rather than using only his/her rational or cognitive skills [5].

With all the respect to and the criticism we have on the different religious establishments, there are also some good things to be said on the religious philosophy and on the devotion and the dedication of most of their personnel. According to our perception all religions have the same goals and intentions. They wish to make good, promote just, while bringing salvation to their followers. They promise the poor to make their life easier and for the suffering believers, who experience Hell on Earth, they promise Paradise. Understandably each religion is the product of its people, geography and specific surroundings. So, the promises and the punishments, the daily practices and the periodical ceremonies, all are built in accordance with the relevant geopolitical environment. The very religious Nomad Bedouins in Saudi Arabia and the loyal Native American in Northern Canada, all worship God, but follow a totally different set of rules and traditions. As compensations for those promises all religions ask their followers to be loyal believers, to respect and follow all the religious rules and to run decent life. Nothing could be said about these demands.

As an IsraeliJew, the Author is a non-religious believer, whose faith rests on the Bible, as the canonical book, and the extensive Jewish philosophy and legacy. This heritage provides us with some basic guiding principles that were pioneering at their time and are relevant up to these days. Keeping the Sabbath, for rest and relaxation after six working days, is among the early social time-outs known in history.

\section{What Is Culture?}

\subsection{Definitions}

A. "The arts and other manifestations of human intellectual achievement regarded collectively."

B. "The customs, arts, social institutions, and achievements of a particular nation, people or other social group" [6].

Culture, in its way, is the manifestation of the non-religious intellectual individuals. Although there are many religious believers who seek and promote culture, it comes secondary, after the religious obligations. One may add that civilization is the social structure that combines both, religion and culture. There is no question that mutual interrelations exist between those two forms of social and intellectual expressions. As previously mentioned, Samuel Huntington had identified nine Civilizations. Thus, it makes sense assuming that by $3-5$ cultures per civilization, some fifty cultures exist all around the globe.

Before going further, we have to clarify some issues regarding culture: 


\subsection{Culture and Sport Activities}

It is our clear opinion that Sport activities, of allfields, should be incorporated within the Cultural human actions. Sport activities, according to the above definition, clearly are manifestations of human physical achievements. They should not be distinguished from the intellectual ones. Football, or soccer, nice played, seemed much like men's Ballet, but with eventually more audience. Physical achievements are important to human-beings and create Culture not less than intellectual achievements. Recent medical findings even indicate that Sport and physical activities, aerobic and anaerobic exercises, prolong life, increase the quality of life and even delay mental deterioration. Thus, a meaningful inspiring and challenging life, a one that enables achieving intellectual actualization, justifies the containing of Sport activities within Culture.

\subsection{The Building Blocks of Local Culture}

We begin the discussion on the Local Culture because of the belief that home should always be the departing point. Rational writers not always properly assess the amount and significance personal and emotional elements have on people's and group's behavior. Since Culture is defined as manifestation of human emotions, it is clear that the nature, type, and forms of cultural expression is strongly connected to it geographical, national and traditional origins. Without having these features, culture cannot move, fly, or be dispersed, internationally.

\subsubsection{Culture as the Manifestation of the Surroundings}

As stated, Culture manifests the spiritual, the intellectual and the physical achievements of a given group, society or a nation. It is therefore, natural, that culture rests and is connected to a given piece of land or a given geographic location. These connections combine, therefore, territorial, environmental and metrological conditions for the creation of social and spiritual conditions that originate culture. Those conditions enable and even encourage the emergence of spiritual and philosophical contemplations and the building-up of different cultural activities.

The historical fact that most spiritual and philosophical roots of the Western Civilization were laid, some thousand years ago, around the Mediterranean, just supports this argument. Ancient Egypt, the Holy Land, Greece and Rome, Persia and Cartago, are all Social-Political entities that are located in this area. Among these auxiliary conditions that promote the creation of knowledge and culture were: modest living conditions, year division into four seasons, very helpful for agriculture, moderate climate, that avails long periods of clear sky, crucial for astronomists and philosopher, and relative stable political regimes that minimized wars. No wonder that some of the world's most valuable remarkable cultural creations, like the Bible, the Egyptian Pyramids, the ancient Greeks' scripts and the Roman Codex originated and executed within this Mediterranean area. 


\subsubsection{Language as a Critical Ingredient of Culture}

Language is among the most critical ingredients of any culture. An opulent language produces a rich culture and vice-versa. The verbal form of human expressions is among the major contributors to wordy branches of culture, like Poetry, Literature, Theater, etc.

Some of the greatest writers of all times, like Shakespeare in England, Jan Jack Russo in France, Hayne in Germany, Servants in Spain and Tolstoy in Russia, are among the prominent cultural heroes of the world. Since language maintains most of society interrelations it is also responsible to many open and hidden connections between groups and individuals. In this way, language affects and is affected by social moods, tendencies and fashions.

In general, congruence exists between the language and the given geographic unit. One nation has only one language and therefore one culture dominate there. There are only few countries, like Canada or Belgium, which have two languages, or Switzerland, which has three official languages, and therefore, a mix of three cultures. Another indication on the true or false importance given to the language could be seen from the EU decision to respect each of the members' original language. Such a decision, that was accepted mainly because of the members' national pride, is quite an economic burden and not always rational. However, it clearly indicates the importance and respect nations give to their language.

A different, though interesting cases are the countries that were in the past colonies ruled by European nations. These were for example, India and other countries in South-East Asia, Nigeria and other countries in Africa. In those countries, English and French were the Languages of the colonialists and they became the official language of the state. The indigenous citizens continue to use their historical language for day to day business. Thus, the European Languages became the ones that unite the countries and support the new coming regime and culture while the original dialects remain for home use. These are the cases were two languages and two cultures are running in parallel, making everyone happy.

In Arabic, the language of many Moslem countries there is a differentiation between the Classical literary version and the daily common language. This distinction exists beside the various dialects characterizing the separate countries. Such a differentiation enables the Moslem to uphold basically one culture that rests on and uses the classical version of the language.

\subsubsection{Culture and Non-Verbal Forms of Fine Arts}

This is a whole world of expressions and manifestations, creating and performing. In the past, and in some less-developed countries even recently, limits were placed upon certain arts. Today, in the free World, nothing of these limitations actually remained. Thus, and in some way, it is also a kind of an absurd, everyone can freely write, play, sing, dance, paint and do whatever he/she thinks or feels. Multi-culture is legitimated, and in some way, even the leading 
trend. The ultimate judge today is the public and nothing could be done against it. The first and foremost requirement from culture remains to be original, authentic and truly representing the people's feelings. Modern culture which lacks such roots usually seems to be transparent, superficial and dilettante.

Whereas Language-oriented Culture is mostly local because it is based on domestic grounds and traditional ingredients, the non-verbal cultural expressions are much more boundaries-free and international. Most of Sport activities, musical concerts and similar performances are based on emotional and nonverbal-effects, so they can be generally understood. This type of cultural manifestations is, therefore, spread around the globe and is subject to international trends and fashions.

\subsection{Post-Modern Culture}

Most of the described in the previous sections was relevant up to the end of the former millennium. Due to the remarkable development of technology, during the past few decades and the unprecedented changes in the communication and the cellphone industries, most previous rules of the game have totally changed.

These changes have tremendously affected many facets of cultural life.

\subsubsection{Culture and the Internet}

The Internet, together with the Cellphone, and its Smartphone derivatives are, could be termed as the Hardware of the system, through which, communication is transferred. In the past, the Internet was designed to be used for computers while the Cellphone was designed for mobile personal communication. However, during the past years and due to further technological advancements, many differences between those systems disappeared as both serve all the requirements-computers replace cellphones and vise-versa. Both systems provide computation and communication services and are growing exponentially. Whereas it is understandable that computation requirements grow fast, because it indicates the growth of scientific inquiry, and this is a very positive development. But nobody can explain why personal cellphone communication outbreak so fast?

With the introduction of computers, the issue of man-machine linkage, that had started with the popular automobile, had grew and got a substantial boost with the unprecedented spread of the cellphones. The Internet has a very important and positive impact on social and cultural life in the $21^{\text {st }}$ Century. It is a simple, not-expensive popular and available instrument for promoting culture, knowledge and in some way even wisdom, all over the country. It had shifted learning out of the universities and availed it to the general public. The Internet had initiated and continues to conducts the Information Democratization process. It also assisted in enabling a renewed flourishing of cultural events. In this capacity the Internet opened doors, gates and packages of opportunities that never been previously available for millions of users. In this way they got new 
information tracks, more musical, audio and video channels and easy knowledge resources.

The Internet also encouraged the establishing of Wikipedia-the Free Encyclopedia, which today is the main track for the Democratization of Knowledge. By so doing the Internet is among the important bodies that permanently contributes to the enhancement of popular know how and culture. Wikipedia became an accepted replacement of libraries. In this way the Internet became the most popular instrument for collecting information acquiring knowledge and spreading them. This also is the reason, why the Internet is so important and contributes so much, to the general-public education and the proper conduct of cultural life. The Internet is also important in facilitating education for solitude students in remote locations.

However, the Internet has created some less-positive outcomes, that concern us and are discussed below:

1) Endangering the Conventional Learning Process Learning is a process that begins at the kindergarten continues at high-school and university and never stop, even after graduation. Beside knowledge, this process contains experiences, routines and practices that aim to shape students' personality, their future behavior and their cultural life.

Exaggerating and focusing on data collection through the internet may change the proper balance required for a healthy class environment at schools. It puts too much attention on acquiring data while disregarding other required learning activities.

By making data collection so easy it reduces the effort and the urge to learn. A given presumption assumes that education quality is determined by the amount of effort and time investing in acquiring it. The Internet has changed this assumption by making the whole learning process shorter and easier. Danger may rise by moving to the edge and forgetting the essentials, as is said: "easy comes easy goes." Knowing trivia is nice and very entertaining but it is still far away from acquiring theoretical grounds and basic expertise. It is almost like professional Sport, where laying with the ball is just the beginning of the story. Years of tiresome training and hard work are required from those who wish to excel and be professionals. there are neither shortcuts nor free lunches. Human history is full with stories on poor and less-privileged individuals, who work hard and learnt afterward just to finish school and to be qualified later for higher education and professional life. The Internet can shorten the time, but it should not dismiss the urge and the required effort.

In sum, the Internet and Wikipedia, as learning aids are very helpful and provide an essential leverage for learning, and building culture. However, they should not try to replace the education systems.

\section{2) Deteriorating the Universities and Colleges Prestige}

The Internet may endanger the prestige of universities, Higher-education institution and cultural centers, like libraries., as the nations' intellectual bastions. 
It provides an easy and comfortable trail for circumventing the very demanding scientific track. Unfortunately, in US many science and engineering classes are manned mostly by foreign students. Campus experience and students' life becomes just a nice and very inspiring desires.

College or University Diploma is just a respectful artifact to be hanged on the office wall. As the Internet and Wikipedia provide easily the basic data needed, why to spend time in the university or library by reading magazines' articles? When, laypersons and students are satisfied with shallow and trivial information it is quite difficult convincing them that deeper and more serious inquiry is required. Universities should install better learning courses for improving their students competent in coping with real world requirements. The Internet and Wikipedia, if properly used, can assist High-education institutions in attaining this Goal. The question remains whether and how Universities and the internet will know and will be able to successfully cooperate.

\section{3) Declining the Status of the former Knowledge Agents}

Resulting from the developments described in the previous sections, the importance, reputation and status of the traditional Knowledge Agents-Teachers, Professors, Scholars and other Specialists, are declining. Who needs them, when almost everything could be obtained from the Internet or Wikipedia? Why inviting an expert or seeking a specialist when all the required information is available in the Internet? This approach, which slowly becomes the general public's attitude, leads to devaluation of professional skills and declining respect to knowable specialists. Pretending to know everything is one of the Internet negative results, even when its referrers to many. Such an approach leads to denning one of the economic ground-rules, the "Division of Labor" or the "Specialization" principles. As everyone can do everything, why to look for an expert or to be helped by a professional? This mood starts with trivialities but may end with essentials.

The Internet provides a very helpful information for sick or disable persons, but it may lead to doubting and mistrusting the treating medical doctor. A delicate balance should be established between the common knowledge and the expert's expertise. The Jewish tradition teaches that teachers and educators are the most important persons after the parents. Why disregarding this command?

A supporting atmosphere for Dilettantes, Quasi-experts or Seem-to-be specialists, may be emerged due to the Internet. It may also encourage those who have learnt a little, even with Diploma, but know no much. Those who lack the primary demand from intellectuals, admitting "I do not know." Such a society also is a one with low cultural values. Prudent and intelligent people, in contrary, are not ashamed claiming that they do not know. Thus, one may conclude that prudent and intellectual individuals, generally tend to be humble and modest, while less-educated ones, used to be extravagant.

In sum, the rapid advancement of the Digital Technology, with its challenging opportunities and sophisticated gadgets, poses a serious threat to conventional education institutions and culture centers. They have no choice but restructur- 
ing their learning and cultural programs. Some new and attractive courses and lessons should be added. For these missions they must hire and employ good updated and capable teachers, professors and specialists. Such a staff will be able to offer the "Human Touch" so much missing in many institutions.

4) Lowering the Stand of Knowledge and Prudence

Combining the former three tendencies result with changing the attitude about learning, education and the whole world of culture. When information is freely provided by the Internet, and eventually everyone can know everything in no time, there is a big challenge of posing a higher, more comprehensive, and more demanding cultural goal. Fighting against mediocracy, frequently is harder and demands more energy than alleviating illiteracy. The Author's main worry is that the Western Civilization [7] will lose its leadership position in Science, Technology, Arts and Humanities because of laziness, triviality, comfortability and negligence, of the future students. When, due to the Internet, Western countries open so many easier opportunities, when the Capitalist maxim of maximizing incomes and profits, is still so dominant, and when spiritual and cultural satisfaction limp behind, the West's historic stand is questionable. Uplifted vision, inspiring ideas, creative innovators and devoted executers are required for curing the present maladies and pushing the West toward new horizons. Social activists and leaders should respond to the basic question: When the Internet provides trivia data about everything, why to spend long hours in the library, carrying out tiresome learning and boring examinations? It is almost obvious that the coming days will pose before the intellectual and cultural elites of many countries, intellectual and cultural challenges, rarely been considered. Those who will be able to cope with the coming inspiring demands will eventually be able to lead further development.

\subsubsection{Culture and the Various Smartphones}

Cellphones, Mobil-phones and Smartphones are among the most visible and influential inventions emerged and materialized in the 2000s. It seems, that in many countries there are more smartphones than citizens. Consequently, personal meetings and traditional small talks are replaced by electronic gossip. There is no question that smartphones are of great importance and significantly aid for business. However, Mobile phones, smartphones and other sophisticated communication gadgets, are useless without the human users. But what about the users themselves? It seems that they begin to be useless without the assistance of the advance devices. It looks that many of them are not too far from the moment when many will lose their way and will get lost without the cellphone, the WAZE or similar gadgets.

As said, the most advanced smartphone is a $8 \times 4$ inches piece of metal, which incorporates computation, navigation, picture-taking and communication capacities within a very small piece of instrumentation. This small instrument with enormous capacities changes many of human behaviors. It affects people's life and steers their behavior. It rises the wondering whether people's enslavement to 
cellphones is needed and justified? Walking on the streets, watching so many individuals sticking the cellphones to their ears, raises a known question of who enslaves whom? whether human-beings enslave the machine or vise-versa? It is acceptable that talking is a human need, but we wonder what they have so much to say?

The current situation evokes some serious concerns, as is detailed below:

1) What is the danger that Smartphone's jargon, acronyms and abbreviations will deteriorate ordinary language quality?

Due to their size and form, Smartphones use different jargon and particular acronyms and abbreviations for delivering their messages. In fact, they set-up a new kind of language that fits their requirements. Recurrent users, youngsters in particular, who were grown up while using permanently this jargon, may forget the taste and the value of a proper classical language. Since Language is the supporting mother of many verbal branches of culture, such a threat should worry all the culture's sponsors.

2) Does the exaggerated use of personal electronic linkage endanger friendship and alienated Human Touch?

The smartphone's breakthrough, which adds many benefits to daily life, also had accelerated their use for personal needs. This tendency endangers the former tradition of human touch and personal good manners. Here also, the problem lays with the young generation that is using Smartphones from their early days. They will be used to communicate through machines, that cannot smile while greeting, do not know crying when suffering and lack the human touch so needed for encouraging. It is to be a different world, whether it is better or worse, who knows?

3) What are the threats and challenges, that shallowness and mediocracy, pose before the Post-modern Western Culture?

Thousands and hundreds of years had passed for developing and enriching the contemporary Western Civilization. It was based on the Judeo-Christian legacy of hard-work, meticulousness, dignity, diligence and devotion. Neither short-cuts nor free-lunch were allowed. While at present, due to the technological revolution of our time, everything comes fast and is easier. The danger is that many will disregard their parent's legacy and will seek ways for easier and joyful life. Many of them also will be satisfied with mediocrity and will not care about shallowness, provided their wishes will be met. Academicians, thinkers, teachers and social leaders must pay attention to this point while seeking proper solutions.

The above issues are important enough for having a separate discussion and article. Since the scope of this work is limited it is recommended to find the proper opportunity for carrying further this study. All that has been said here is just a general worry that other professors and students, should pay attention to it.

\section{Me, Religious and Culture}

All along this essay we tried to concentrate on the "soft" aspects of human life. 
Economists, state-persons and politicians deal much with the "real" world-the world of economics, business and money, which were mentioned here only by-the-way.

We have chosen to study the intangible issues since we believe that they are the ones, which are going to influence westerners at the coming decades. Most citizens of the western countries came to a point were materialistically, they are well off, but still they worry about the future. $\mathrm{Me}$-the creative individual, Religion-the leading believing in unknown divinity, and Culture-the whole area of Arts and Humanity, are the main concern of the writer.

This triad also is the core structure and spiritual essence of every civilization.

The present essay concentrates on the situation at the Western Civilization, it starts with examining the past but offers some prospects for the future. For that purpose, it is helpful to cite some ideas offered by John Naisbitt [8] and Patricia Aburdene (1990) n their book "Megatrends 2000." These megatrends are detailed in the Introduction section while here we only note some comments about their relevancy.

However, four out of Naisbitt's ten Megatrends, those, which are germane to our topic, no. 2, 4, 9, and 10 still are relevant with some changes, to our time, some thirty years afterward. With all respect it is difficult to point out today on Renaissance in Arts. It -is true that arts change, although they have the same meanings-manifestation of human emotions-their form, shape and volume change and their audience grow tremendously. Global Lifestyle flourishes today due to the new Media and the Smartphones technology. Cultural Nationalism, mainly in sport activities, thrive, due to better international games and extra-large communication means. The New Millennium witnesses a Religious Revival, because many feels frustrated from the poor results of the existing political-economic systems. They seek better salvation for their soul and spirit. The last megatrend, the Triumph of the Individual is very important. It could wisely be recovered by setting up a dynamic considering balance, between individual entrepreneurs and irresponsible egotists. A creative and innovative individualism-Me, in this essay, is among the critical leverages and the crucial prerequisite, for leading groups, organizations and nations toward better days.

\section{Conclusions}

The triad, $\mathrm{Me}$ - the creative Individual, Religion-the endless uncontainable Universe, and Culture-the spiritual sphere that envelopes us all, are the core structure and the spiritual essence of every civilization. All participating parties must realize that their keen existing depend on their competence to fairly collaborate, and promote mutual appreciation.

The world of today is changing. In the Post-modern era of the $21^{\text {st }}$ Century, nothing is certain. At present, the only certain thing is the uncertainty. This situation encourages religious people to seek God for salvation and non-religious 
individuals to promote escapism. Laypersons and talented ones, are divided between creative, irresponsible and egotistic individuals. All the groups, the immortal religion worshipers, the proponents of multifaced culture and the general public participate in this remarkable transition that looks, sometimes, like a revolution. In this chaotic world, full with challenging innovations and threatened by inhuman terror groups, members of the Western Civilization must have an inspiring vision and exciting goals. They should convince their fellow citizens that the triad of devoted People, comforting Religion and multifaced Culture, can bring Pleasure and Happiness to Earth.

\section{Conflicts of Interest}

The author declares no conflicts of interest regarding the publication of this paper.

\section{References}

[1] Wikipedia (2019) Sigma Is the 18th Letter in the Greek Alphabet and Is Equivalent to Our Letter 'S'. In Mathematics, the Upper-Case Sigma Is Used for the Summation Notification.

[2] Avny, A. (2019) Technology and Society in the Digital Era. Journal of Philosophy Study. (In Print)

[3] Marx, K. (1800-1800) A German Philosopher, the Founder of the Marxism Movement.

[4] Wikipedia (2019) Religion Definition.

[5] Goleman D. (1997) Emotional Intelligence. (Hebrew Edition) Matar Publishers, Tel Aviv.

[6] Wikipedia (2019) Emotional Intelligence by Goleman.

[7] Huntington, S. (1996) The Clash of Civilizations, (Hebrew Edition 2003) Shalem Center, Jerusalem.

[8] Naisbitt, J. and Aburdene, P. (1990) Megatrends 2000. Avon Books, New York. 